\title{
Fidelity of Peer Mediation and its Role in Improving Students' Oral English Communication Skills
}

\author{
Betegiorgis Mamo ${ }^{1}$ and Abiy Yigzaw ${ }^{2^{*}}$ \\ ${ }^{1}$ Department of English and Literature, Debre-Birhan University, Debre-Birhan, Ethiopia \\ ${ }^{2}$ Department of English, Faculty of Humanities, Bahir Dar University, Bahir Dar, Ethiopia
}

\begin{abstract}
The purpose of this study was to examine fidelity of peer mediation and its role in improving students' oral English communication skills at Debre-Berhan University. A Communicative English Skills class was randomly selected as a study group. From this class, high- and medium together with low- performing students in oral English communication skills were identified as peer mediators $(\mathrm{N}=15)$ and mediatees $(\mathrm{N}=61)$, respectively. The mediatees were categorized into medium and low achieving peer groups, each of which comprised five members, including one peer mediator assigned randomly to the group. During a three-week teacher-led session, the peer groups were trained in the peer mediation procedures that involved mediation strategies for enhancing such aspects of oral abilities as organization of related bits of information, succession of events and description of individual qualities in personal introduction. The findings revealed that there was an acceptable level of agreement between both the peer mediators and the mediatees on fidelity of the peer mediation as they rated the fidelity checklist. Pre-to post-test oral communication scores significantly improved for low and medium achievers as a result of the peer mediation. Based on the findings, recommendations were made for purposes of examining sustained practicality of peer mediation toward improving students' learning and performance in oral English communication skills.
\end{abstract}

Article Information

Copyright@2015 STAR Journal, Wollega University. All Rights Reserved.

Article History:

Received : 15-02-2014

Revised : 26-03-2015

Accepted : 29-03-2015

\begin{tabular}{l} 
Keywords: \\
Peer mediation \\
Fidelity of peer mediation \\
Peer mediators \\
Mediatees \\
Oralish Communication Skills \\
\hline *Corresponding Author: \\
Abiy Yigzaw \\
E-mail: abiyyigzaw@yahoo.com
\end{tabular}

\section{INTRODUCTION}

Peer mediation is a student-centred method that allows students to work together in small peer groups whereby group members have specific roles and responsibilities to practice group-based activities (Richards and Schmidt, 2002). As a system for teaching high, medium and low-ability students in cooperative groups, peer mediation engages students actively in their learning through a student assisting others on difficult tasks by providing problem-solving strategies (Ashman and Gillies, 2003). It is noted that the use of peers as facilitators within the teaching-learning context is one of the common pedagogical approaches that assists students who experience a range of learning difficulties as well as a variety of teaching-learning settings (Ashman, 2003). Because there will always be a number of students in every class who learn very quickly and there will be some who do not, so to maximize the learning of the latter peer mediation is an effective strategy to allow a more able student to assist group peers on difficult tasks (Ashman and Gillies, 2003). It is highlighted that instructional approach involving students in peer assistance is a part of a significant shift in educational practices to provide new opportunities for student-centred active learning at higher education institutions (Gafney and Varma-Nelson, 2008). Such pedagogical approach to learning fosters the value of students' cooperative voices, interactions and experiences in the construction of knowledge and the encouragement of classroom peer learning communities (Castaòeda, 2005). Research studies have demonstrated that peer support learning at institutions of higher education has resulted in a number of gains in student social learning and academic performance in a wide range of courses (Falchikov, 2001; Gafney and Varma-Nelson, 2008).

From the social interactionists' point of view in particular, language learning relies heavily on meaningful social interactions within social and cognitive support for helping learners to improve their language and conceptual understanding (Dunlap and Weisman, 2007). This perspective of learning rooted in Vygotsky's (1978) sociocultural theory of mediated learning and cognitive development which emphasize the crucial role of interacting with significant others (such as more capable peers) assisting one another in order to internalize new information and skills (Vygotsky, 1978). Vygotsky argued that meaning is socially constructed; hence learning and cognitive development can be affected by the interactions an individual has with another who is more skilled or knowledgeable(Ashman and Gillies, 2003:199). It is highlighted that peer interaction and support is a natural part of the social classroom where more capable peers 
scaffold or mediate learning by providing the language and problem-solving strategies so that students stuck for learning are able to complete tasks they could not do alone (Ashman and Gillies, 2003; Pritchard and Woollard, 2010). In language learning classroom in particular, peer support affects learners' motivation for language learning (Law, 2011); that is, working in small peer groups tends to increase students' motivation through interaction (Wrench et. al. 2009). Such learning structure has been proved so useful particularly in the foreign language learning that it is easier to get learners to use the target language directly with a partner or in a group as it is less threatening than speaking up in class (Dam, 2011). In other words, peer support helps learners cope with language anxiety, build confidence and retain feedback from peer partners (Hurd and Lewis, 2008). In the English as a Foreign Language (EFL) context in which students' exposure to the target language is largely in the classroom (Mingzhi, 2005; Nguyen, 2013), peers appear to be an important source of language learning (Gauvain, 2005; Carter and Kennedy, 2006). Overall, it is understandable from the talking point presented so far that the benefits of learning experiences mediated by peers to student social learning, motivation and achievement in academic performance are worth considering.

Given the pedagogical importance of peer support learning for providing a substantial shift in educational practices from teacher-centred instruction to a studentcentred active learning, the rationale for employing peer mediation in the present study pertaining to improvement of students' oral English communication skills are threefold. Primarily, a number of studies conducted to assess implementation of active learning methods in Ethiopian higher education institutions reported that most lectures in universities adhere to traditional teaching methods (Melaku et. al., 2013), and instructors had low practice of active learning methods because of their tendency toward traditional/lecture method (Aschalew, 2013). Research into EFL learning context in particular revealed that language instructors rarely applied active learning methods in their classroom because they had lack of experience and problems of using different active learning methods to implement CLT methodology effectively toward improving students' English language skills (Anto et. al., 2012; Tessema et. al., 2012). This is one of the factors that can be accounted for student communication problems as studies conducted on quality of higher education in Ethiopian public institutions indicated that most university students lack communication skills and do not have a reasonable level of communication skills or proficiency in English (Amare et al., 2009; Yared, 2012). In this connection, it is, however, underscored that the current trend of globalization calls for students to be proficient in oral communication skills in English so that they can function effectively in the academic and professional settings (Rahman, 2010). This remains true in the Ethiopian context in particular (MoE, 2012), English has a central place in the Ethiopian higher education institutions for its pivotal role in educational development and service as a medium of instruction.

To help undergraduate students improve English communication skills which are presently critical problems, English common courses like Communicative English Skills is currently offered across all Ethiopian public universities (HESC, 2009). With one of its major aspects of emphasis on oral communication skills practice, the course Communicative English Skills, which is the focus of the present study, is designed to provide various oral activities for student active learning which include working in group for personal introduction, roleplaying, debating and oral presentations that help students develop effective oral language use in English (DBU, 2010). It is, however, reported that although the course Communicative English Skills is intended to help university students overcome their difficulty in communication skills, many of the students perform insufficiently in the course because of problems attributed to their poor English language background, low proficiency and lack of skills in social interactions (Anto et al., 2012).

The second justification for the study has stemmed from that though peer assistance among mixed ability students is articulated as a norm and crucial pedagogical initiative to foster more active student learning, such instructional strategy remains untapped in the Ethiopian higher education institutions, particularly in Communicative English Skills classes. This is evidenced in a study by Anto et al. (2012) that though there were students with outstanding, medium and low oral communication performances in the Communicative English Skills classes, the English teachers actively engaged only outstanding students in the teachinglearning process, instead of giving students a chance to work in groups or pairs. Nevertheless, in a learner-centred classroom, collaboration among students is the norm so that the students teach, help and critique each other (Doyle, 2008), and they have enough time to think, rehearse, and receive feedback in contrast to teachercentred classes (Pishghadam and Ghardiri, 2011). Vygotsky (1978) basically expounds that more capable peers can be potential resources to enhance learning processes and cognitive development of less capable peer partners when both are working in collaboration. The study by Anto et al. (2012) further indicated that the teachers usually prefer to use teacher-dominated methods and they actively engaged only outstanding students in the teaching learning process, without being worried about medium and slow learners. It is, however, underscored, "In learner-centred classrooms, students regularly teach their peers [, so] it is our [the teachers'] job to help them develop the basic skills and confidence to do this" (Doyle, 2008:107). To this end, it is suggested that teachers should create justifiable peer support structure in which they can assign students into heterogeneous groups on the basis of ability as a result of which more capable peers can be potential resources to support the learning of their peer partners (Wilkinson and Fung, 2003). Because such a heterogonous mix of students as high, medium and low performers in language learning provides an opportunity for peer-assisted learning among students of different language skills toward overcoming language barrier and encouraging on-task behaviour (Richards, 2002; Dunlap and Weisman, 2007).

Finally, the study may make a significant contribution to the "cooperative team learning"(commonly called "oneto-five" peer grouping) which has been launched by Debre-Berhan University (2014) as university-wide instructional processes in which high, medium and low achieving students learn together being assisted by a high achieving student. Despite launching such an instructional programme, the university indicated in its assessment report that the result achieved remains unsatisfactory 
because teachers do not implement peer group learning strategy based on clarity beyond structuring students in "one-to-five" cooperative learning teams. The report is underpinned by a small-scale research study that the majority of EFL teachers at Debre-Berhan University conceived peer-assisted learning differently than the university expected it to be for the reason that they had incredulity in the benefits and effectiveness of its newly introduced structure (Betegiorgis and Abiy, 2015, in press).

\section{Oral Communication Skills}

Oral communication skills are so crucial and broad that, according to Isabelli-Garcia (2000) and Rahman (2010), they cover a gamut of abilities with wide-ranging definitions. Busa (2010), for instance, says oral communication skills, which are also referred to as speaking skills, are essential aspects of social interaction necessary to engage in conversations, transmit information, express opinions, ideas and contribute to discussions. Moreover, in Kouicem's (2010) view, speaking is useful to tell stories and display different functions of language. As for Isabelli-Garcia, 2000), oral communication skills are the use of specific speech functions by the non-native speaker pertinent to oral communication skills practice with the aim of learning a target language and exchanging information with others using that particular target language. In another definition, oral communication is to mean formal oral presentations which may include all prepared, extemporaneous, or impromptu speeches to participation in discussions and meetings in order to put across messages to audience (Rahman, 2010). In the context of the present study, the concept of oral communication skills is defined according to Ur's (2006) description that effective delivery of speech involves fluency aspect, that is, how easily, well and effectively ideas are orally communicated, and accuracy of speech in terms of vocabulary and grammar.

\section{Teaching and Learning of Oral Communication Skills in an EFL Context}

Oral English communication skills teaching and learning is of paramount importance to students' academic performance and their future professional career. According to Widiati (2006), the teaching of speaking or oral communication skills has become increasingly important in English as a second or foreign language (ESL/EFL) because of its strengthening position as a language for international communication and academic studies. In fact, teaching and learning oral English communication skills in an EFL context basically requires an understanding of peculiar problems with a view to taking considerations necessary to make the learning process effective. One of the problems is that learning English in an EFL context is largely limited to students' exposure to classroom practice (Deckert, 2004), and the students have little exposure to English outside the classroom to practice their newly acquired language skills (Camenson, 2007; Khan, 2010). For this reason, oral communication skills in English are harder for students to develop (Camenson, 2007; Khan, 2010). It is pointed out in particular that oral English communication skills are harder for students to develop in EFL classes as there are fewer practice opportunities for communicating in the target language than for those learning in the target community (Khan, 2010). Likewise, Brown and Yule (2001) state that learning to speak in English is not only a challenge for EFL students but also is often considered to be one of the most difficult aspects of language learning for the teacher to help the student with. Bashir et al. (2011) also note that learning to speak or communicate orally in English is viewed so difficult that it demands a lot of practice and attention. Given this reality, Riasati and Noordin (2011), however, noted that EFL teachers need to bear in mind the fact that the EFL classroom is the best, if not the only, place where learners should get an opportunity to practice oral English communication skills interactively. Because most EFL learners learn the target language in their own culture and practice is mostly available in the classroom, a key factor in L2 or foreign language development is the opportunity given to EFL learners to interact in the classroom (Shumin, 2002). Classroom interaction is thus a routine that needs special attention in EFL teaching, in which case it is necessary for teachers of EFL to carefully examine the factors, conditions, and components that underlie effective instruction for successful speaking abilities (Ibid.).

Furthermore, it is argued that humans are born with the ability to vocalize, but not with the knowledge, attitudes, and skills that define communication competence, so the ability to communicate effectively and appropriately is learned and thus must be taught (Morreale, et al., 2000). This is more specifically highlighted by Bahrani and Soltan (2012) that if the goal of language course is truly to enable students to communicate in English, then speaking skill should be taught and practiced in the language classroom. This shows that special importance should be given to the English classroom to provide students with more opportunities to practice their English speaking skills for effective communication. In this connection, it is suggested that as opportunities for L2 learning is usually less accessible in comparison with English as a Second Language (ESL) context, peers appear to be an important source of learning for EFL learners (Nguyen, 2013). Oral language development in particular for ESL/EFL students requires support with peers (Zgutowicz, 2009). For example, the support more capable peers offer may include communicative techniques such as clarifying instructions and ideas, providing prompts, hints and demonstrations, asking comprehension questions, and praising to increase participation of less capable students in the learning process (Carter and Kennedy, 2006; Gauvain, 2005). Such support for language learning in general and oral communication skills learning in particular is grounded in Vygotsky's (1978) notion of the zone proximal development (ZPD) to be discussed subsequently.

\section{Language Learning in Vygotsky's ZPD}

Language learning is inherently embedded in social interactions within a supportive environment from the perspective of social interactionism (Dunlap and Weisman, 2007). Social interactionism is a pedagogical perspective which emphasizes the importance of social interaction to successful learning (Pritchard and Woollard, 2010). Social interactionism ascribes success in second/foreign language learning to social interactions carried out between or among students (Lantolf, 1994). This perspective has its origins in Vygotsky's (1978) sociocultural theory of mediated learning which lays emphasis on the role of social interaction with others and assistance one another as a crucial process to learning and cognitive development. Sociocultural theory is concerned with the ability of peers to provide guidance 
and feedback to one another during collaborative dialogue in the learning process (Stevens, 2008). Such a learning process is central to Vygotsky's notion of the ZPD which embodies the difference between what a learner can accomplish alone and what she or he can do with assistance from a more capable person such as a teacher or peer (Martin-Kniep and Picone-Zocchia, 2009). In a similar vein, Bot et. al. (2005) describe ZPD as the variation between the 'actual developmental level' which refers to what a learner can perform independently and the 'zone of proximal development' that includes those functions and activities that a learner can perform only with the support of an adult (parent, language instructor) or another peer who has already mastered that particular function. Learning a language, in particular, depends to a large extent on social and cognitive support (Dunlap and Weisman, 2007); and simultaneously, language and cognitive development influence each other, in such a way that social interaction is necessary for language to fully blossom (Dunlap and Weisman, 2007).

Therefore, an opportunity for social interaction provides learners with more peer assistance which is a natural part of the social classroom in which learners who become stuck on the learning process can more readily seek advice and support from others (Pritchard and Woollard, 2010). In other words, if social interaction is to be elevated specially to help students achieve cognitive and linguistic self-regulation in the foreign language classroom regardless of their linguistic competence, one of the mechanisms is to provide them with collaborative group tasks involving peers having different knowledge as well as experience (Coyle, 2005). Thus, the ZPD is the primary activity space in which learning takes place leading to internalization of skills and knowledge being transformed from the social into the cognitive plane (Walqui, 2006). To this end, the more-less capable peer group in which learners work collaboratively is a central participation structure for learning within Vygotsky's ZPD whereby the more capable partner (whether teacher, or peer) can assist and guide the less capable participants by modelling, scaffolding, and exemplifying pedagogical activities (van Lier, 2004; Hopkins, 2010). A broad range of research along the line of Vygotsky's ZPD has resulted in cognitive development, including language or speech improvement from social interaction with adults or more able peers (van Lier, 2004; Walqui, 2006; Van der Veer, 2011).

Overall, while Vygotsky believes learning and development takes place within the ZPD with the assistance given by a more capable mediator, he nevertheless seems to have any systematic principles or techniques that should guide how collaboration should be conducted by the mediator during a jointly accomplished task (Chaiklin, 2003). The gap in Vygotsky's ZPD has been addressed in Feuerstein's Mediated Learning Experience (MLE) as discussed in more detail subsequently.

\section{Feuerstein's Mediated Learning Experience (MLE)}

Feuerstein, similar to Vygotsky, developed his Mediated Learning Experience (MLE) approach based on the social constructivist perspective and as an augmentation of the sociocultural theory of learning (Presseisen and Kozulin, 1992). Both Vygotsky and Feuerstein, being social constructivists, share a common interest in social interaction as a basic feature of mediated learning, but Feuerstein differs from Vygotsky in important ways because he gives greater importance to a human mediator who is instrumental in actualizing social interaction for one's mediated learning and cognitive development (Kozulin et. al., 2003). Of course, in the process of actualizing social interaction, Feuerstein draws heavily on Vygotsky's ZPD which he has elaborated in the MLE approach as part of his theory of Structural Cognitive Modifiability (SCM), with an emphasis given to human mediation by significant others such as parent, caregiver, teacher, or more knowledgeable peer (Mentis et. al., 2007). Because Feuerstein views that not each interaction involving a task, learner and mediator possesses a quality of mediated learning experience, but an interaction becomes MLE only when facilitated by a human mediator who has intent to make the interaction meaningful to a learner (Smith et. al., 2005). For the purpose of describing the role of human mediation and the quality of the interactive environment in his MLE approach, Feuerstein has thus developed a modality of learning that owes greater emphasis to a human mediator (Tan and Seng, 2008).

\section{Criteria of Mediated Learning Experience (MLE)}

Feuerstein's MLE describes a special quality of interaction between a learner and a mediator whose role is to interpose intentionally between the learner and learning activities to provide meaningful interactions (Smith et. al., 2005). For this purpose, Feuerstein developed 12 criteria describing the role of human mediation and the quality of learning interaction (Mentis et.al. 2007). The criteria are instrumental in the learningteaching process, leading the learner ultimately to use the criteria for autonomous task performance (Feuerstein et. al., 1991); and therefore, effectiveness of learning intervention is determined not only by the design of the strategies or exercises but more importantly by characteristics of the mediation process (Tan and Seng, 2008). In other words, any interactions between a mediator and a learner cannot be recognized as mediated learning experience unless they constitute attributes of MLE that distinguish them from other types of interaction (Poehner, 2008). In terms of their instrumental role in the instructional process, MLE criteria provide a very specific and functionally operational basis for grounding what is learned, why it is learned, and how the learning can be applied to new learning and the demands of a changing environment (Hopkins, 2010). Among the twelve criteria, Feuerstein considers the first three MLE parameters (intentionality, transcendence, and mediation of meaning) universal and core attributes because they transcend not only culture but also the modality of mediation in different social and cultural contexts and they are most commonly applicable in learning programmes (Tan and Seng, 2008). These three criteria are common to all MLEs so that they need to be accounted for in every learning exchange that constitutes MLE which leads to the development of uniquely human forms of higher thinking (Presseisen and Kozulin, 1992; Poehner, 2008). The remaining nine criteria are not to be considered exhaustive, but they are used as necessary for a learning context (Kozulin, 2003).

For the purpose of the current study, the first three criteria of mediation, which are referred to as universal, including two other MLE parameters (feelings of competence and self-regulation and control of behaviour) are chosen as appropriate for justifications to be discussed in detail in the methodology section of the 
study. Accordingly, the five MLE criteria include: intentionality and reciprocity, transcendence, meaning, feelings of competence, self-regulation and control of behaviour. Mediation of intentionality and reciprocity is concerned with helping the students focus their attention on and realize the importance of an interaction on a task so that they can look at the significance of the task to their own and in a broader cultural context (Kozulin et. al., 2003). With intentionality, the mediator concentrates on assisting the learner to understand how he or she is using his or her cognition toward approaching and performing a learning task (Mentis et. al., 2007). Regarding reciprocity, the learner and the mediator need to consider one another as on the "same level" which is to mean that the mediator does not pretend to know the answer as to how the learner should be thinking (Gonzalez et. al., 2008). Transcendence is to do with an effort exerted by a mediator to explain to the students how their involvement in a particular learning task will help them in future task performance beyond the immediate needs and situation at present only (Mentis et. al., 2007; Tan and Seng, 2008). In essence, the mediator assists the learner to go beyond the information given and to connect the present learning activities with both the past and the future than to master specific bits of here-and-now data (Presseisen and Kozulin, 1992), leading the learner to transfer lessons, rules and methods learned from one experience to another learning situation (Gonzalez et. al., 2008). In mediation of meaning, the mediator interprets for the learner the significance of what is or has been accomplished using various ways to cause him/her to reflect not just on the solution to the problem but also on how the solution has been obtained and the generalizations that flow from it (Gonzalez et. al., 2008).Mediation of feelings of competence is to do with the mediator' role in enhancing the learner's confidence and involvement in task performance by encouraging him/her to perceive that he/she has the ability to do a learning activity (Mentis et. al., 2007). Regarding mediation of self-regulation and control of behaviour, the mediator encourages the learner to take responsibility for his/her own learning and independent task performance (Tan and Seng, 2008), through assisting in task planning and controlling task performance (Brown, 2002). Overall, the five MLE criteria, taken together in an integrated manner, are thus used as instrumental to qualify oral communication interactions enhanced using Feuerstein's mediation strategies.

\section{Feuerstein's Instrumental Enrichment}

Feuerstein' Instrumental Enrichment (IE) provides a set of strategies or exercises which are designed to foster a learner's development of cognitive functions and problem-solving abilities in terms of MLE (Poehner, 2008). Accordingly, in attempt to overcome students' problems in oral English communication skills diagnosed using Ur's (2006) speaking rubric pertaining to the present study, mediation strategies corresponding to the above mentioned MLE criteria and relevant to the speaking lessons to be taught are taken from Feuerstein's IE. The mediation strategies include: analytic perception exercise which focuses on the relationship between a whole and its parts in a task, and ways a whole can be divided into parts, and then parts are joined into a whole (Poehner, 2008). This strategy helps to overcome students' inability to provide complete or precise descriptions about a task (Mentis et. al., 2007). Temporal relations is the other strategy that facilitates students' understanding of time concepts and their relationship to verbal tenses as well as vocabulary usage in order to describe past, present and future events or actions in a chronological order (Mentis et. al., 2007; Poehner, 2008). Comparisons is a further strategy that enhances students' ability to systematically compare objects and events according to set criteria in order to develop critical thinking toward organizing and integrating distinct bits of information into meaningful systems (Poehner, 2008).

\section{Merging of Vygotsky's ZPD with Feuerstein's MLE}

The merger of Vgotsky's ZPD and Feuerstein's MLE is widely recommended for pedagogical practices. According to Cheng (2011), the ZPD and Feuerstien's MLE should be applied together for the most persuasive justification that MLE describes what comes about within the ZPD. In brief, the gaps in Vygotsky's notion of the ZPD have been addressed by Feuerstein's MLE which assigns specific roles to human mediators (Kozulin et. al., 2003; Cheng, 2011), specifically mediation criteria and corresponding strategies for the enhancement of learning and cognitive development within the ZPD (Feuerstien et. al. 1991). Research studies of those inspired by merger of Vygotsky's ZPD with Feuerstein' MLE (e.g. Shamir et.al. 2006; Cawthon, 2009; Cheng, 2011) have revealed that integrating Feuerstien's MLE into Vygotsky's ZPD is a very substantial theoretical underpinning and effective intervention for the development of students' learning abilities, language and cognitive skills. To this end, this study integrates Vygotsky's ZPD with Feuerstein's MLE criteria to draw up a conceptual framework which forms the basis of peer mediation to be examined for its implementation fidelity toward improving students' oral English communication skills.

\section{The Role of Peer Mediation in Oral English Communication Skills}

Language learning central to peer mediation is a conversation whereby the less proficient or capable students are aided by their more proficient peers in a small collaborative peer group learning process (Walqui, 2006). The underlying foundation of such learning process is Vygotsky's notion of ZPD which explicates the perspective that a less capable learner can perform one level of skill independently with appropriate support gained from more capable peers in collaborative social interaction (Vygotsky, 1986). For the purpose of such instructional process, students are taught roles by their teacher and, through these roles, the students systematically instruct other students, during which the teacher monitors and facilitates pupils' progress (Hall and Stegila, 2003). Research studies conducted in EFL/ESL contexts at universities from Vygotsky's ZPD perspective have shown positive outcomes of peer mediation. For example, peer mediation improved students' speaking skills in English (Hucrng, 2004), and developed their ideas, content knowledge, skills in pronunciation and oral presentation (Nguyen, 2013). Similar other studies reveal that peer interactions developed students' English speaking skills and enhanced their capacity to generate new language (Kouicem, 2010), augmented students' effective learning and oral communicative competence in the EFL classroom (Kouicem 2010; Garcia, 2010), and improved their understanding of the content of different subjects offered through English (Garcia, 2010). Further studies conducted in middle schools showed that peer mediation appeared better to raise students' awareness of the crucial factors involved in effective oral communication 
such as reporting information accurately for well-informed opinions and decisions (Herrera, 2009), and offered learners the opportunity to participate actively in class discussions by providing peer modelling and practice (Linan-Thompson and Vaughn, 2007).

This study, therefore, aimed at examining fidelity of peer mediation and its effects on students' oral English communication skills in the Communicative English Skills classroom at Debre-Berhan University. The study attempts to provide practical implications for sustained implementation of peer mediation to enhance students' oral English communication skills learning and performance. With this end in view, the researchers devised the following research questions:

1. What is the fidelity of peer mediation implementation in oral English communication skills learning?

2. What effect does the peer mediation have on students' oral English communication skills?

\section{MATERIALS AND METHODS}

This study followed a single-subject design and used a quantitative approach to examine fidelity of peer mediation and its effects on students' oral English communication skills in the Communicative English Skills class. To analyze data about fidelity of the peer mediation, percentage was used, and mean and standard deviation were used to provide descriptive summary of the pre- and post-test oral communication skills measures. Besides, paired sample t-test was employed to test whether there was a statistically significant difference between the preand post-test measures on students' oral English communication skills.

\section{Participants}

This study involved a class of students taking the course Communicative English Skills at Debre-Berhan University in the 2014/15 academic year. This class was randomly selected for the peer mediation programme from 54 Communicative English Skills classes. The class was an accounting major and it had 76 student numbers. Participant students were identified, based on speaking English performance, as peer mediators who were presumed potential resource to enhance other students' oral English communication skills learning, and as those of mediatees who were in need of such learning enhancement through peer mediation. Selection of participant students is explained in more detail subsequently.

\section{Instruments}

The following two instruments were used to gather data from participant students in the peer mediation.

\section{Rubric for Speaking Skills}

To assess students' oral English communication skills before and after the peer mediation, Ur's (2006) speaking rubric was adapted and employed. This rubric has been primarily designed to assess spoken English, especially in an EFL context, and it comprises fluency and accuracy as its major components, each of which carries scale of oral communication criteria described at five levels ranging from 1 to 5 (Ur, 2006). The fluency scale comprises such aspects as how easily, well and effectively ideas are orally communicated, and accuracy includes the ability to speak English with sufficient vocabulary and correct grammar. A student's overall performance in oral English communication skills is thus determined by adding values gained from fluency and accuracy scales, and calculating the total sum out of 10 . Accordingly, students with 2-4.5, 5-7.5 and 8-10 scores were treated in this study as low, medium and high achievers, respectively.

\section{Checklist for Peer Mediation Fidelity}

Fidelity of implementation is a necessary condition to ensure that a peer-led instruction is implemented as intended and successful as possible right from the intervention (Gafney and Varma-Nelson, 2008). It is pointed out that in order to ensure that peer-mediated learning strategies are implemented as an effective intervention with high fidelity, class-wide peer-mediated learning strategies need to be observed with teachers receiving feedback about their quality of implementation (Abbott et. al, 2011). Thus, to assess fidelity of the peer mediation implementation, a checklist was adapted from the mediation questionnaire which has been originally developed by Feuerstein et. al (1991)( Mentis et. al., 2007). The adapted checkilist comprises the five MLE criteria discussed above being aligned closely with description of behaviours of both the peer mediators and the mediatees in joint oral communication mediation practice. The checklist has 22 items, and each item is answered by 'yes' or 'no' response as regards occurrence or absence of mediated learning behaviours (experiences). The checklist was administered to the peer mediators and the mediatees following completion of the peer mediation intervention. To describe and interpret the results from the peer mediation checklist, percentage of the peer mediators, medium achievers and low achievers who rated the twenty two items of the checklist saying either "yes" or "no" was calculated using Sulzer-Azaroff and Mayer's item-by-item overall percentage agreement method, i.e., agreements divided into agreements + disagreements $\times 100$ (Sarafino, 2012). Then the group respondents' percentage agreement on each item was averaged to calculate and check interrater reliability or agreement on implementation of each MLE criterion pertaining to oral communication skills practice. Interrater agreement check was conducted in accordance with David and Cheney's (2004) suggestion that no matter what method of recording behaviour is used to examine the level of agreement among raters who independently record occurrence of a target behaviour in a wide variety of educational settings and interventions, $80 \%$ and above interobserver agreement, as set by Sulzer and Mayer, is generally acceptable level of reliability. It is pointed out that $80 \%$ agreement or higher is reported in virtually all published research using systematic observation of one or more specific target behaviours coded by such instruments as checklists (Brown et.al., 1999). Such interrater percentage agreement check is used as a conventional method in a peer-mediated learning context in which $80 \%$ and above interrater agreement between the mediator/tutor and the mediatee/tutee on mediation activities regarded as acceptable level for effective and sustainable implementation of peer-mediated strategies to enhance the learning of English language skills (Fuchs, Fuchs, Mathes and Simmons, 1997; Greenwood et. al., 2001).

\section{Participant Student Selection and Training}

Selection and training of participant students in a peermediated instructional or intervention programme is one of the integral components recommended for effective 
implementation of peer mediation strategies or peer support interventions (Frea andVittimberga, 2000; Ashman and Gillies, 2003; Gafney and Varma-Nelson, 2008; Carter and Kennedy.2006; Abbott et. al., 2011). Therefore, subsequent to obtaining informed oral and written, respectively, consents from pertinent body of Debre-Berhan University and the target class teacher for implementing the peer mediation programme, the researcher briefed students in the target class on the peer-mediated learning programme and thus a written agreement was gained from each student to participate in the programme. Then, to select participant students for peer-mediated learning, the researcher prepared two individual oral presentation pre-tests on the topics of personal introduction and description of personal appearance and qualities which were all drawn from speaking tasks presented in the introductory unit of the course material. In the administration of the tests, two TEFL from Debre-Berhan University, being oriented on procedures for the speaking tests, used Ur's (2006) speaking skills rubric and assessed each student's oral performance on the two pre-tests with a week time gap between each of the tests during the regular class time. Based on an average of scores on the two speaking tests, the students who got high $(n=15)$ as compared with their classmates, and those students who obtained medium $(n=28)$ and low $(n=33)$ all together were identified as peer mediators and mediatees, respectively. The respective average scores of the peer mediators, medium achievers and low achievers were in the range of 8-9, 5-7.5 and 24.5 out of 10 , as assessed using Ur's speaking rubric.

\section{Participant Teacher and Student Initial Training in Peer Mediation}

Training requiring a minimum of $1-3$ days is essential for teachers who have never implemented peer-mediated strategies in order to acquaint the teachers with general implementation of peer-mediated learning their roles, the different materials and procedures to be used in such instructional programme (Abbott et. al., 2011). Cognizant of the desirability of teacher training in peer mediation according to report of a study that the majority of EFL teachers at the setting of this research had limited understanding and implementation of peer-assisted learning (Betegiorgis and Abiy, 2015, in press), the researcher gave a nine-hour initial training to the target class teacher to introduce him to general concept of peer mediation, objectives and implementation of a set of scripted oral communication lessons designed for peer mediation in the Communicative English Skills classroom. According to Abbott et. al. (2011), such training includes activities as teacher presentation, student practice, teacher facilitation, supervision and feedback during the peer-mediated learning. By doing so, the target class teacher was prepared for implementing the peer mediation. Similarly, peer leader or mediator training in peer-mediated strategies prior to implementation is essential to the success of such instructional programme (Gafney and Varma-Nelson, 2008; Abbott et. al., 2011). This training covers establishing rules, social behaviours and procedures for appropriate peer mediation in task presentation, error correction, and in praise of correct responses or performance (Abbott et. al., 2011). Therefore, the class teacher along with the researcher conducted six-hour training sessions using a set of scripted oral communication tasks illustrating peer mediation procedures in order to introduce the target class students identified as peer mediators to the peer- mediation strategies with corresponding objectives, respective roles assigned to them and the mediatees in the peer-assisted group learning process. During the training, questions, reflections and feedback from the student trainees were encouraged to create a clear understanding of issues under discussion and prepare the trainees for implementation of oral communication strategies using practice materials.

\section{Practice Material for the Peer Mediation}

For the enhancement of students' oral communication skills learning through peer mediation, practice materials were prepared as an aid for the peer mediators and the mediatees based on the objectives stated in the course material for the development of speaking skills in English. The practice materials contained four oral communication exercises adapted from the course material and then developed in light of Feuerstein's MLE and mediation strategies designed for the enhancement of learning and cognitive functions. The oral communication exercises were personal introduction, usage of tenses, time expressions and vocabulary in personal introduction as well as in description of student life experiences, respectively. These four exercises were designed for practice with suitable mediation strategies drawn from Feuerstein's MLE instruments which included: analytic perception, temporal relations and comparisons. The analytic perception exercise was presented in a diagrammatic representation to enhance students' thinking skills in organizing parts and bits of information in personal introduction, especially by looking at all the parts separately and conjointly. The temporal relations exercise was intended to develop students' understanding of past, present and future verbal tenses as well as time and place expressions through working at chronological order of events or information in personal introduction. Comparisons exercise provided students with vocabulary building practice through comparison of individuals in terms of physical appearance and personal qualities (i.e., student working habits and hobbies). All the four oral task mediation strategies were implemented in an integrated manner to address students' fluency and accuracy in oral English which were identified as two problem areas in the two pre-tests (i.e., personal introduction and description of personal appearance and qualities). In brief, the two pretest scores and speech data taken from the students informed the researcher that many students had little/no language production, poor/limited vocabulary and mistakes in basic grammar with respect to accuracy. Analogously, fluency in English speaking was prevalent among the students, in such as way that most of the students had little/no communication, and they communicated very hesitantly, or used utterances sometimes difficult to understand. The oral communication mediation strategies above were thus designed in the light of these problems.

\section{Participant Student Training in Peer Mediation Implementation}

For training student participants in peer mediation implementation during the regular class time scheduled for speaking skills learning in the course Communicative English skills, the students were organized into two groups, i.e., low and medium performing peer groups according to the speaking pre-test data. There were 7 and 8 low and medium performing peer groups in total, respectively. Then, high achieving students $(n=15)$ were each assigned randomly to each of the peer groups. 
There were thus five members in each of the peer groups, in which one was peer mediator and the other four were mediatees. In keeping the peer mediators and mediatees with their respective peer groups periodically throughout the peer mediation, the teacher trained the peer groups in mediation practice which lasted for a total of six periods, each had 50 minutes. During this time, the teacher distributed four practice sheets containing the above mentioned mediation strategies to the peer groups and introduced them to oral tasks with corresponding objectives and time required for the tasks. He then explained to the peer groups such peer mediation procedures as peer mediator-mediatee interactions at the pre-task stage to deal with brainstorming questions relevant to the task to follow, collaborative, assisted and individual oral task performance at while-task and posttask stages, and offering praise or correction on performance, and error correction. Thereafter, each peer group periodically engaged in these procedural routines in which the peer mediator employed analytic perception, temporal relations and comparisons strategies or exercises to guide and assist peer partners to learn collaboratively, actively discussing and talking each other. The peer mediator accomplished such specific activities as presenting the mediation strategies for supporting the peer group to focus attention to details of the oral tasks, facilitating peer group discussions, showing clues as to how the peer group complete the oral tasks, modelling the peer group in personal introduction and description, and encouraging the mediatees in individual task performance as well as presentation. The peer mediator thus attempted to help the mediatees build abilities and confidence in oral skills by allowing them tell answers to the peer group and share experiences one another. During such peer-led learning, the teacher facilitated and monitored the progress of instructional process by moving among the peer groups and encouraging verbally appropriate peer mediation behaviours. In the mean time, the researcher followed up the peer mediation in progress and provided the teacher with technical assistance as deemed necessary. Overall, subsequent to completion of each peer-mediated oral task, the teacher together with the researcher held discussions with participant students in order to gain whole-class feedback on the peer mediation in progress for on-going training in the strategies designed relevant to the oral tasks.

\section{Data Gathering}

By administrating the fidelity checklist following completion of the peer mediation, data were collected from both the peer mediators. Similarly, an individual oral presentation post-test on the topic, "Student Life at High School and University", which was similar to the topics for the pre-tests, was conducted to assess medium and low performing students' oral communication skills improvement as a result of the peer mediation.

\section{RESULTS AND DISCUSSION}

A total of fifteen peer mediators and sixty one mediatees (medium achievers, $n=33$, and low achievers, $n=28$ ) filled in the peer mediation fidelity checklist. Of these, responding to the items pertaining to mediation of intentionality and reciprocity, that is, whether or not the peer mediator aroused the peer student's interest in oral communication skills practice, whether or not the peer mediator listened and responded to the peer student in a supportive way to learning, and whether or not the peer mediator showed interest in the peer student's oral communication skills practice, $86.67 \%, 73.33 \%$ and $80 \%$ of the peer mediators, $81.82 \%, 78.79 \%$ and $72.73 \%$ of the medium achievers and $82.14 \%, 85.71 \%$ and $89.29 \%$ of the low achievers agreed on each item that the stated mediation activities occurred during the peer-mediated learning. The respondents had thus $82.89 \%, 80.26 \%$ and $80.26 \%$ overall percentage agreement on each item, respectively. In this connection, Abbott et al (2011) state that peer-mediated strategies allow students to get motivated with social rewards to engage actively in learning, practice and learn academic content from their peers and become accountable for their achievement. The levels of agreement on implementation of similar other items describing mediation of intentionality and reciprocity such as if the peer mediator was happy when the peer student made progress in oral communication activities, and if the peer mediator provided the peer student enough information before asking questions were correspondingly $100 \%$ and $93.33 \%$ for the peer mediators, $66.67 \%$ and $75.76 \%$ for the medium achievers and $92.86 \%$ and $78.57 \%$ for the low achievers. As can be seen from these percentage scores of the respondents, the peer mediators and the low achievers were in close agreement in the occurrence of the first mediational behaviour as compared to the medium achievers. In spite of this, the overall interrater percentage agreement of the participant students on the two items was thus $82.89 \%$ and $80.26 \%$, respectively. In response to the items related to mediation of meaning, that is, whether or not the peer mediator explained the importance of oral communication skills mediation strategies to the peer student, and if the peer mediator encouraged the peer students to focus attention on the oral communication exercises, $93.33 \%$ and $100 \%$ of the peer mediators, $72.73 \%$ and $75.76 \%$ of the medium achievers, and $82.14 \%$ and $78.57 \%$ of the low achievers were in agreement on each item that the stated mediation activities occurred in the learning process. As a result, the overall percentage agreement among the participant students on the two items was $80.26 \%$ and $81.58 \%$, respectively. Percentage agreements as to whether or not the peer mediator provided the peer student clear information about the oral communication activities, and whether or not the peer mediator appreciated the peer student's answers and ideas during peer group discussions were on each item $86.67 \%$ and $80 \%$ for the peer mediators, $69.71 \%$ and $78.79 \%$ for the medium achievers, and $89.29 \%$ and 92.86 $\%$ for the low achievers. The participant students' overall percentage agreement on each item was thus $81.89 \%$ and $83.88 \%$, respectively. Such acceptable levels of interrater reliability can be considered in relation to the explanation made by Kuh et al (2006) that peers are very influential to student learning and values development by providing feedback in a conversation about how the student is performing.

Regarding the items related to mediation of transcendence such as whether or not the peer mediator showed the peer student connections between past, present and future events in oral communication, and whether or not the peer mediator provided examples and encouraged the peer student to find relationships between aspects of oral communication such as usage of tenses, time and place expressions, and vocabulary. $93.33 \%$ and $86.67 \%$ of the peer mediators, $75.76 \%$ and $81.82 \%$ of the medium achievers and $78.57 \%$ and $85.71 \%$ of the low achievers agreed that the stated mediated learning experiences occurred during the peer mediation. 
Therefore, the participant students had $80.26 \%$ and $84.21 \%$ average agreement corresponding to each item. Agreement on the item stating that the peer mediator showed the peer student the relationship between the specific content and general purpose of oral communication skills was $80 \%, 63.64 \%$ and $67.86 \%$ for the peer mediators, the medium achievers and the low achievers, respectively. The overall percentage agreement was thus $68.42 \%$ which is below $80 \%$ interrater agreement set as an acceptable level of reliability. With reference to items stating mediation of feelings of competence, that is, whether or not the peer mediator told the peer student how he/she could perform the oral communication activities successfully, and whether or not the peer mediator checked the peer student's understanding of the oral communication activities during the peer mediation, $86.67 \%$ and $93.33 \%$ of the peer mediators, $75.76 \%$ and $81.82 \%$ of the medium achievers and $82.14 \%$ and $78.57 \%$ of the low achievers were in agreement in their respective responses to each item that the mediated learning experiences under discussion occurred during the peer mediation. As a result, the respective overall agreement on the two items was $80.26 \%$ and $82.89 \%$. Similarly, the percentage of peer mediators, medium achievers and low achievers who agreed on the item that the peer mediator offered the peer student positive responses, even if his/her answer and performance was unsatisfactory were $100 \%, 72.73 \%$ and $85.71 \%$, respectively. The overall percentage agreement was thus found to be $82.89 \%$. However, in response to the item stating that the peer mediator showed the peer student his/her strengths and progress in oral communication activities, there was low agreement among $66.67 \%$ of the peer mediators, $54.55 \%$ of the medium achievers and $75 \%$ of the low achievers. Then the overall percentage agreement was $64.47 \%$. As for occurrence of mediated learning experiences pertaining to mediation of self-regulation and control of behaviour such as whether or not the peer mediator encouraged the peer student to follow rules during individual task performance, and the peer mediator's encouragement for the peer student to reflect ideas and answers without interruption, $80 \%$ and $100 \%$ of the peer mediators, $81.82 \%$ and $84.85 \%$ of the medium achievers and $82.14 \%$ and $75 \%$ of the low achievers indicated their agreement corresponding to each item. Therefore, the participant students had $81.58 \%$ and $84.21 \%$ overall interrater agreement on each of the items, respectively. Likewise, overall percentage agreements on the items stating that the peer mediator showed the peer student strategies to perform oral communication activities and the peer mediator encouraged the peer student to focus attention on the oral activity, think before answering, and check his/her own work were $80.26 \%$ and $81.58 \%$, respectively (peer mediators, 93.33\% and $86.67 \%$; medium achievers, $78.79 \%$ and $75.76 \%$; low achievers, $75 \%$ and $86.67 \%$ ). Abbott et al (2011) reported that some evidence suggests that peer-mediated strategies improve social skills and student on-task behaviour in social interactions. On the contrary, agreement as to whether the peer mediator assisted the peer student to plan and perform oral communication activities was $73.33 \%, 60.61 \%$ and $64.29 \%$ for the peer mediators, medium achievers and low achievers, respectively, and therefore, the overall interrater agreement was found $64.47 \%$. Similarly, with regard to the item stating that the peer mediator allowed the peer student to evaluate his/her oral activities being responsible for his/her learning, $66.67 \%$ of the peer mediators, $69.71 \%$ of the medium achievers and $69.71 \%$ of the low achievers indicated agreement, as result of which the overall interrater agreement was found to be $72.37 \%$. The overall agreements reported here above (i.e. $64.47 \%$ and $72.37 \%$ ) are below $80 \%$ which is set a minimum standard for acceptable level of reliability. This may call for Frea and Vittimberga's (2000) idea that thought the intent of peer-mediated strategies is that the peer provides all of the support for social interaction within the classroom environment, it is reasonable to assume that some peer tutors need additional support, such as teacher prompting and reinforcement to effectively the social facilitation strategies.

Generally, in the light of the results from the peer mediation fidelity checklist, eighteen items $(81.82 \%)$ out of the twenty-two items $(100 \%)$ received the level of overall percentage agreement recommended as desirable for effective and sustainable implementation of the peermediated learning strategies. This shows that the participant students jointly implemented such MLE criteria as mediation of intentionality and reciprocity, meaning, transcendence, feelings of competence, and selfregulation and control of behaviour in the practice of oral communication mediation strategies (i.e., analytic perception, temporal relations and comparisons) to the reliability of $81.82 \%$ overall agreement. In other words, the results show that the peer mediators were able to provide mediated learning experiences for peer partners, especially in oral communication skills practice. This implies that peer mediators are capable of implementing mediated learning strategies in oral communication skills lessons when they are trained in doing so. McMaster et al (2007) assert that that once the students are proficient with peer-assisted learning strategies procedures, they can devote their full attention to successful practice in the actual content of the lessons. Therefore, it should be acknowledged that it is still imperative for the class teacher to train the peer mediators and the mediatees in implementation of the four items to help them be competent to carry out peer-mediated learning strategies and reach the acceptable level of interrater reliability. Abbott et al (2011) underscore that in order to ensure peer-mediated strategies are implemented with high fidelity, peer-mediated learning needs to be observed with teachers receiving feedback about their quality of implementation.

With regard to statistical analysis of data derived from the oral communication skills assessments, the consistency of the two pre-test measures was first determined using Pearson correlation $(r=.78)$. Since the two pre-test measures were adequately correlated, the average of the two tests is taken as a measure of pre-test for further analysis.

Table1: Descriptive summary of pre-and to post-test oral performance scores of low- \& medium- achievers

\begin{tabular}{lcccc}
\hline \multicolumn{1}{c}{ Student ability group } & Min & Max & Mean & SD \\
\hline Low achievers (n=28) & & & & \\
Pre- test & 2 & 4.75 & 3.16 & 0.89 \\
Post-post & 3 & 7 & 4.79 & 0.94 \\
\hline Medium achievers (n=33) & & & & \\
Pre- test & 4.75 & 7.25 & 5.79 & 0.70 \\
Post-post & 6 & 8 & 6.88 & 0.61 \\
\hline
\end{tabular}


Table 2: Paired sample t-test for low achievers and medium achievers

\begin{tabular}{|c|c|c|c|c|c|c|c|c|}
\hline \multirow[b]{3}{*}{$\begin{array}{l}\text { Low achievers } \\
\text { Pre-to post-test }\end{array}$} & \multicolumn{8}{|c|}{ Paired differences } \\
\hline & Mean & SD & St-error & $95 \% \mathrm{C}$ & ence Int. & $\mathbf{t}$ & df & $\begin{array}{c}\text { Sig. } \\
\text { (2-tailed) }\end{array}$ \\
\hline & -1.63 & 0.53 & 101 & $\begin{array}{l}\text { Lower } \\
-1.83\end{array}$ & $\begin{array}{c}\text { Upper } \\
-0.45\end{array}$ & -16.055 & 27 & \\
\hline $\begin{array}{l}\text { Medium achievers } \\
\text { Pre-test - post-test }\end{array}$ & -1.08 & 0.47 & .08 & -1.25 & -0.915 & -13.11 & 32 & 0.000 \\
\hline
\end{tabular}

As can be seen in Table 1, there is a statistically significant difference in pre-to post-test measures on oral communication skills as a result of the intervention given to the low achievers, $\mathrm{t}(27)=-16.055(P<0.001)$, indicating higher post-test score $(\mathrm{M}=4.79, \mathrm{SD}=0.94)$ than pre-test average score $(M=3.16, S D=0.89)$. Similarly, the intervention resulted in statistically significant improvement on pre-to- post-test oral communication scores of medium achievers, $\mathrm{t}(32)=-13.11,(P<0.001)$, showing higher post-test score $(M=6.88, S D=0.61)$ than pre-test average score $(M=5.79, S D=0.70)$. From the paired sample t-test provided in Table 2, it can be concluded that both low and medium achievers scored high in the post-test in comparison with their pre-test score as a result of the peer mediation intervention. However, the degree of influence that the intervention had on students was found to be comparatively higher among low achievers than the medium achievers.

\section{CONCLUSIONS}

This study examined fidelity of peer mediation and its effects on students' oral English communication skills in the Communicative English Skills class. The findings reveal that participant students implemented oral communication mediation strategies procedurally as planned during training in peer mediation. This was evidenced by the overall agreement between the peer mediators and the mediatees for the implementation of eighteen items $(81.82 \%)$ out of the twenty-two items $(100 \%)$ listed in the fidelity checklist, with a range of 80.26 $\%$ to $84.21 \%$. This overall percentage agreement is regarded as the level desirable for effective and sustainable implementation of peer-mediated learning strategies. Therefore, the results from the peer mediation fidelity checklist shows that the participant students jointly implemented such MLE criteria as mediation of intentionality and reciprocity, meaning, transcendence, feelings of competence, and self-regulation and control of behaviour in the practice of oral communication mediation strategies (i.e., analytic perception, temporal relations and comparisons) to the reliability of $81.82 \%$ overall agreement. As for effects of the peer mediation students' oral performance, low and medium achievers showed significant pre-to post test improvement in their oral English communication skills as a result of the peer mediation intervention, though the improvement was found moderately higher among low achievers than medium achievers. The findings lead to the conclusion that training of student peer group in mediation strategies with adequate integrity is a necessity for an effective peerled instructional intervention designed to enhance students' abilities in academic performance. Research by Shamir et al (2006) demonstrates that that training students in peer mediation is an effective way to prepare them for a peer mediation style that enhances both the peer mediator's and the mediatee's learning how to learn skills and, in consequence, their learning and academic achievements. Finally, it is suggested that future research take results gained from this study as a starting point for sustained implementation of peer mediation toward improving students' oral English communication skills.

\section{Conflict of Interest}

Conflict of interest none declared

\section{REFERENCES}

Abbott, M., Greenwood, C. R., Buzhardt, J. Wills, H.P. and Barbara Terry, B. (2011). Peer-Mediated Approaches. In R. E. O'Connor and P. F. Vadasy (Eds.), Handbook of Reading Interventions (pp.279-299), U.S.A: The Guilford Press.

Amare, A., Ayele, S., Dawit, M., Mulu, N., Tesfaye, S., Wana, L., Wossenu, Yimam, Yalew, E. and Yohannes, W. (2009). Quality of Higher Education in Public Institutions. Forum for Social Studies (pp.1-266), Addis Ababa, Ethiopia.

Anto, A. G., Coenders, F. and Voogt, J. (2012). Assessing the Current Implementation of Communicative Language Teaching for English Language Teachers in Ethiopian Universities. Staff and Educational Development International 16 (1): 51-69.

Aschalew T. (2013). Teachers' Perceptions and Practices of Active Learning in Haramaya University, Eastern Ethiopia: The Case Of Faculty Of Education, An International Multidisciplinary Peer Reviewed and Journal I(IV):370390.

Ashman, A. F. (2005). Peer mediation and students with diverse learning needs. In R., M. Gillies and A., F., Ashman (Eds.), The Social and Intellectual Outcomes of Learning in Groups (pp. 87-102), U.S.A: The Taylor and Francis Group.

Ashman, A. F. and Gillies, R. M. (2005). Guiding intellectual and personal growth across educational contexts. In R. M. Gillies, and A. F. Ashman (Eds.), The Social and Intellectual Outcomes of Learning in Groups (pp.224238), U.S.A: The Taylor and Francis e-Library.

Bahrani, T. and Soltan, R. (2012). How to Teach Speaking Skill? Journal of Education and Practice 3(2): 25-29.

Bashir, M., Azeem, M. and Dogar, A. H. (2011). Factor Effecting Students' English Speaking Skills. British Journal of Arts and Social Sciences 2(1): 34-50.

Betegiorgis, M. and Abiy, Y. (2015in press). EFL Teachers' Conceptions and Attitudes of Peer-Assisted Learning in English Classes. Ethiopian Journal of Social Sciences and Language Studies xx: xxx-xxx.

Bot, D., Lowie, L. and Verspoor, M. (2005). Second Language Acquisition: An Advanced Resource Book. New York: Taylor and Francis e-library.

Brown, D. (2002). Mediated learning and foreign language acquisition. Asp: 35-36, 167-182.

Brown, G. and Yule, G. (2001). Teaching the Spoken Language: An approach based on the analysis conversational English. United Kingdom: Cambridge University Press. 
Brown, K.W. Cozby, P.C., Kee, D.W. and Worden, P.E. (1999). Research Methods in Human Development. U.S.A: Mayfield Publishing Company.

Busa, G.M. (2010). Sounding natural: improving oral presentation skills. Language Value 2(1): 51-67.

Camenson, B. (2007). Opportunities in Teaching English to Speakers of Other Languages. U.S.A: The McGraw-Hill Companies.

Carter, E.W. and Kennedy, C.H. (2006). Promoting Access to the General Curriculum Using Peer Support Strategies. Research and Practice for Persons with Severe Disabilities 31(4): 284-292.

Castaòeda, C.R. (2005). Teaching and learning in diverse classrooms: faculty reflections on their experiences and pedagogical practices of teaching diverse population. U.S.A: The Taylor and Francis e-Library.

Cawthon, C.H. (2009). Small-Group versus One-on-One Educational Therapy for Struggling readers and Writers. Unpublished doctoral dissertation, Barry University.

Chaiklin, S. (2003). The Zone of Proximal Development in Vygotsky's Analysis of Learning and Instruction. In A. Kouzlin, B, Gendis, V., Agryev, andS. M. Miller (Eds.).

Cheng, X. (2011). Knowledge of Mediation and Its Implementation among Secondary School EFL Teachers in China. Theory and Practice in Language Studies1(9): 1111-1121.

Dam, L. (2011). Developing Learner Autonomy with School Kids: Principles, practices, results. In: D. Gardner (Ed.), Fostering autonomy in language learning (pp..40-51) Gaziantep: Zirve University. http://ilac2010.zirve.edu.tr

David, W.P. and Cheney, C. D. (2004). Behavioural Analysis and Learning. ( $3^{\text {rd }}$ ed.).U.S.A: Lawrence Erlbaum Associates, Inc.

Debre Berhan University Department of English (2010). Debre Berhan University Curriculum for a Three Year Undergraduate English Language and Literature Degree Programme. Unpublished working document.

Debre-Berhan University Learning-Teaching Core Business Process (2014).Cooperative Learning and Team Teaching Building Implementation Plan. Unpublished document, Debre-Berhan University.

Deckert, G. (2004). The Communicative Approach: Addressing Frequent Failure. English Teaching Forum, 12-17.

Doyle, T. (2008). Helping Students Learn in a LearnerCentred Environment: A guide to facilitating learning in higher education. U.S.A: Stylus Publishing, LLC.

Dunlap, C. Z. and Weisman, E. M. (2006). Helping English Language Learners Succeed. U.SA: Shell Education.

Ervin, R. A. and Ehrhardt, K. E. (2000). Behavior Analysis and School Psychology. In J. Austin and J. E. Car (Eds.), Handbook of Applied Behavior Analysis (pp.113-136). Canada: Context Press.

Falchikov, N. (2002). Learning Together Peer Tutoring in Higher Education. New York: the Taylor and Francis eLibrary.

Feuerstein, R., Klein, P. S., and Tannenbaum, A. (1991). Mediating Learning Experience (MLE): theoretical, psychological and learning implications. London: Freund Publishing House Ltd.

Frea, W. D and Vittimberga, G. L. (2000). Behavioural Interventions for Children with Autism. (2000). In J. Austin and J. E. Car (Eds.), Handbook of Applied Behavior Analysis (pp.247-274). Canada: Context Press.

Fuchs, D., Fuchs L. S. Mathes, P.G. and Simmons, D.C. (1997). Peer-Assisted Learning Strategies: Making
Classrooms More Responsive to Diversity. American Educational Research Journal, 34, (1), 174-206.

Greenwood, C, R, Arreaga-Mayer, C. Utley, C. .A, Gavin, K. M. and Terry, B. J. (2001). Class Wide Peer Tutoring Learning Management System: Applications with Elementary-Level English Language Learners. Remedial and Special Education, 22, (1), 34-47.

Hall, T., and Stegila, A. (2003). Peer-mediated instruction and intervention. Wakefield, MA: National Center on Accessing the General Curriculum. Retrieved from http://www.cast.org/publications/ncac/ncac peemii.html

Herrera. F., P. (2009). Cooperative Structures of Interaction in a Public School EFL Classroomin Bogotá. Colombian Applied Linguistics Journal: 13(1), 20-23.

Hurd, S. and Lewis, T. (2008).Introduction. In S. Hurd and T. Lewis (Eds.). Language Learning Strategies in Independent Settings (pp. xii-xviii). Great Britain: The Cromwell Press Ltd.

Gafney, L. and Varma-Nelson, P. (2008). Peer-Led Team Learning: Evaluation, Dissemination, and Institutionalization of a College Level Initiative. U.S.A: Springer Science.

Garcia, D. S. (2010). Classroom interaction in university settings: the case of questions in three disciplines. Master's thesis, University Madrid.

Gauvain, M. (2005). Sociocultural Contexts of Learning. In A. E. Maynard, and M. I. Martini (Eds.), Learning in Cultural Context Family, Peers, and School (pp. 11-41). New York: Plenum Publishers.

Gonzalez, H. L., Palencia, A. P., Umana, L. A. and Galindo, L. (2008). Mediated learning experience and concept maps: a pedagogical tool for achieving meaningful learning in medical physiology students. American Physiological Society Advances in Physiology Education, 32(4), 312-316.

Higher Education Strategy Center. (2009). Harmonized Curriculum for English Common Courses for Under Graduate Degree Program. Unpublished working document. Addis Ababa, Ethiopia.

Hopkins, K., R. (2010). Teaching How to Learn in a What-toLearn Culture. U.S.A: Jossey-Bass.

Hucrng, L., P., H. (2004). A Sociocultural Analysis of Learning English in Unassisted and Assisted Peer Groups at University in Vietnam. Unpublished doctoral dissertation, Victoria University of Wellington.

Isabelli-Garcia, C. (2000). Development of Oral Communication Skills Abroad. The Interdisciplinary Journal of Study Abroad, 9,149-175.

Lantolf, J. P. (1994). Sociocultural Theory and Second Language Learning: Introduction to the Special Issue. The Modern Language Journal, 78(4), 418-420.

Law, E, Y. Y. (2011). Evaluating Learning Gain in a SelfAccess Centre. In D. Gardner (Ed.), Fostering autonomy in language learning (pp.199-213). Gaziantep: Zirve University. Retrieved from http://ilac2010.zirve.edu.tr

Linan-Thompson, S. and Vaughn S. (2007). Adaptations of Peer-Assisted Learning for English Language Learners: Application to Middle-School Social Studies Classes. Unpublished research overview. University of Texas at Austin.

Khan, S. (2010). Strategies and Spoken Production on Three Oral Communication Tasks: A study of High and Low Proficiency EFL Learners. Unpublished doctoral Thesis, Universitat Autònoma de Barcelona.

Kouicem, K. (2010). The Effects of Classroom Interaction on Developing the Learner's Speaking Skill: The case of third 
Betegiorgis Mamo and Abiy Yigzaw

year LMD students of English at Constantine University. Master's thesis, Constantine University.

Kozulin, A. (2003). Psychological Tools and Mediated Learning. In A. Kouzlin, B, Gendis, V., Agryev, and S. M. Miller (Eds.). Vygotsky's Educational Theory in Cultural Context (pp.15-38). U.S.A: Cambridge University Press.

Kozulin, A., Gindis, B., Ageyev, V.S. and Miller, S.M. (2003). Sociocultural Theory and Education: Students, Teachers, and Knowledge. In: A. Kouzlin, B, Gendis, V., Agryev, and S. M. Miller (Eds.). Vygotsky's Educational Theory in Cultural Context (p.1-11). USA: Cambridge University Press

Kuh, G.D., Kinzie, J. Buckely, J. A., Bridges, B. K. and Hayek, J. C. (2006).What Matters to Student Success: A Review of the Literature. Commissioned Report for National Symposium on Postsecondary Student Success: Spearheading a Dialog on Student Success. U.S.A: National Postsecondary Education Cooperative.

Martin-Kniep, G. and Picone-Zocchia, J. (2009). Changing the Way You Teach, Improving the Way Students Learn. U.S.A: ASCD.

McMaster, K.L, Fuchs, D. and Fuchs, L.S. (2007). Promises and Limitations of Peer-Assisted Learning Strategies in Reading Learning Disabilities: A Contemporary Journal 5(2): 97-112.

Melaku M.W., Atagana,H. and Temechengn, E. (2013). Ethiopian university science and technology instructors' attitudes toward active learning International Journal of Science \& Technology Educational Research 4(3):47-56.

Mentis, M., Dunn-Bernstein and Mentis, M. (2007). Mediated Learning: Teaching, Tasks and Tools to Unlock. Cognitive Potential. ( $2^{\text {nd }}$ ed.). U. S.A: Crowin Press, Inc.

Mingzhi, X. (2005). Enhancing Interaction in Our EFL Classroom. Celea Journal 28(2).

Ministry of Education (2012). Education Sector Development Program III (ESDR III) 2005/2006-2010/2011. Unpublished document. Addis Ababa, Ethiopia.

Morreale, S. P. (Ed.). (2009). Competent and Incompetent Communication. $21^{\text {st }}$ Century Communication: A Reference Handbook. Thousand Oaks: SAGE Publications, Inc.

Nguyen, M.H. (2013). EFL Students' Reflections on Peer Scaffolding in Making a Collaborative Oral Presentation. English Language Teaching 6(4): 64-73.

Poehner, M.E. (2008). Dynamic Assessment: A Vygotskian Approach to Understanding and Promoting L2 Development. U.S.A: Springer.

Presseisen, B.Z. and Kozulin, A. (1992, April). Mediated Learning: The Contributions of Vygotsky and Feuerstein in Theory and Practice. A paper presented at the Annual Meeting of the American Educational Research Association, San Francisco.

Pritchard, A. and Woollard, J. (2010). Psychology for the Classroom: constructivism and social learning. U.S.A: The Taylor and Francis e-Library.

Rahman, M.M. (2010). Teaching Oral Communication Skills: A Task-based Approach ESP World 9, 1(27): 1-11.

Riasati, M.J. and Noordin, N. (2011). Antecedents of Willingness to Communicate: A Review of Literature. Studies in Literature and Language 3(2): 74-80.

Richards, J.C. (2002). Theories of Teaching in Language Teaching. In: J.C. Richards and W.A. Renandya, Methodology in Language Teaching: An Anthology of Current Practice. (19-26). USA: Cambridge University.

Richards, J. C. and Schmidt, R. (2002). Longman Dictionary of Language Teaching and Applied Linguistics. ( $3^{\text {rd }}$ ed.). Malaysia: Pearson Education Limited.
Sci. Technol. Arts Res. J., Jan-March 2015, 4(1): 203-214

Sarafino, E, P. (2012). Applied Behaviour Analysis: Principles and Procedures for Modifying Behaviour. USA: John Wiley and Sons, Inc.

Shamir, A., Tzuriel, D. and Rozen, M. (2006). Peer Mediation: The Effects of Program Intervention, Maths Level, and Verbal Ability on Mediation Style and Improvement in Maths Problem Solving. School Psychology International 27(2): 209-231.

Shumin, K. (2002). Factors to Consider: Developing Adult EFL Students' Speaking Abilities. In J. C. Richards and W. A. Renandya (Eds.), Methodology in Language Teaching: An Anthology of Current Practice (pp. 204211). U.S.A: Cambridge University.

Smith, L., Julie Dockrell, J. and Tomlinson, P. (Eds.). (2005). Piaget, Vygotsky and Beyond: Future Issues for Developmental Psychology and Education. London: The Taylor and Francis e-Library

Stevens, R. J. (2008). Coppertaive Learning . In N. J. Salkind (ed.), Encyclopaedia of educational psychology (pp.187193), U.S.A: SAGE Publications, Inc.

Tan, O.S., and Seng, S.H. (2008). Cognitive Modifiability and Cognitive Functions. In O. S. Tan and S. H. A. Seng (Eds.), Cognitive Modifiability in Learning and Assessment: International Perspectives (pp. 1-18). Singapore: Cengage Learning.

Tessema, T.A., Manjula, L.D. and Fikadu, B.(2012). The Role of Instructors in Implementing Communicative Language Teaching Methodology. The International Institute for Science, Technology and Education 2(3): 52-62.

Ur, P. (2006). A Course in Language Teaching: Practice and theory. Cambridge: Cambridge University Press.

Van der Veer, R. (2011). Continuum Library of Educational Thought. Great Britain: Continuum International Publishing Group.

van Lier, L. (2004). The Ecology and Semiotics of Language Learning: A Sociocultural Perspective. U.S.A: Kluwer Academic Publishers.

Vygotsky, L.S. (1978). Mind in society (Edited by M. Cole, V. John-Steiner, S. Scribner, and E. Souberman). Cambridge, MA: Harvard University Press.

Vygotsky, L.S.(1986). Language and Thought (Translated and edited by A. Kozulin). Cambridge: The Massachusetts Institute of Technology Press.

Walqui, A. (2006). Scaffolding Instruction for English Language Learners: A Conceptual Framework. The International Journal of Bilingual Education and Bilingualism 9(2): 159-180.

Widiati, U. and Cahyono, B. Y. (2006).The teaching of EFL Speaking in the Indonesian Context: The State of the Art. Bahasa Dan Seni 34(2): 269-292.

Wilkinson, I.A.G. and Fung, I.Y.Y. (2003). Small-group composition and peer effects. International Journal of Educational Research 37: 425-447.

Wrench, J.S., Richmond, V.P and Gorham, J (2009). Communication, Affect, and Learning in the Classroom. $\left(3^{\text {rd }}\right.$ ed.) U.S.A: Tapestry Press.

Yared N. (2012). Quality of Education in Selected Colleges of Addis Ababa University. A presentation paper at the $21^{\text {st }}$ Annual Conference of the Ethiopian Statistical Association (23-24 March, 2012), Addis Ababa, Ethiopia.

Zgutowicz, R. (2009). What effects does language anxiety have on ESL students' decisions to speak English in a middle school classroom? Unpublished master's thesis, Hamline University. 